Gut, 1964, 5, 599

\title{
A trial of hypnosis in the management of recurrent mouth ulceration
}

\author{
DEREK CHALMERS AND WILFRED SIRCUS \\ From the Department of Dermatology, Royal Infirmary, Edinburgh, and \\ the Gastro-intestinal Unit, Western General Hospital, Edinburgh
}

EDITORIAL SYNOPSIS In view of the frequent relationship of a nervous factor with aphthous ulceration, five patients were treated by suggestion under hypnosis, but unfortunately without any success.

Previous experience has indicated the important role of the nervous system in the production and perpetuation of a substantial proportion of cases of recurrent ulceration of the mouth, especially of the aphthous type (Sircus, Church, and Kelleher, 1957; Sircus, 1959).

Six patients with recurrent ulceration of the mouth which had failed to respond to various forms of treatment, including oral hydroxyquinolone, local corticosteroid, systemic corticosteroid and corticotrophin, and sedation with barbiturates, were invited to undergo a course of hypnosis performed by one of us (D.C.); all agreed. One patient proved unable to cooperate and after three unsuccessful attempts at hypnosis the treatment was abandoned. The other five proved good subjects for hypnosis.

The method used was that of the relaxation type, and the depth of hypnosis obtained was such as to allow post-hypnotic suggestion. The patients received from six to 24 sessions of hypnosis, each lasting approximately 10 minutes and at intervals of two weeks. The two main suggestions made under hypnosis were that the ulcers would heal and not recur and that the patients would be more relaxed in their outlook on life.

\section{CASE HISTORIES AND RESULTS}

CASE 1 P.M., an unmarried woman aged 26 years, had multiple aphthous ulcers of the buccal cavity for seven years, with at most 10 days of freedom in the past 12 months. The patient was very tense about the prospect of her engagement to a doctor and had an unhappy relationship with her family. Previous treatments included oral prednisolone, oral plaquenil, barbiturates, chlorpromazine, triamcinolone in orabase, and local hydrocortisone with only transient benefit from each. She was a good subject for hypnosis and had eight

'Part-time member of the external staff of the Medical Research Council.

8 sessions over four months, but with no effect on the duration or incidence of ulcers.

CASE 2 N.M., a married, childless woman aged 46 years, had recurrent aphthous ulceration of the buccal cavity for 25 years, continuously and without remission during the past year. She had periods of endogenous depression and had features of obsessional and paranoic psychopathology. Previous treatment included systemic, oral and local corticosteroids, hydroxyquinolone, and triamcinolone in orabase. She was a good subject for hypnosis and had eight sessions over four months. While attending for hypnosis the size and incidence of the ulcers fell from an average of six large lesions to three small ones. Within three weeks of ceasing hypnosis sessions she again had crops of several large ulcers and three months later she remained severely affected.

CASE 3 F.C., a married, childless woman aged 51 years, had had multiple aphthous ulcers of the buccal cavity for 30 years, and these had been continuous since the menopause three years before, She was tense, obsessional, and unhappy since her depressive husband's infidelity five years ago. Previous treatment included oral and local corticosteroids. She was a good subject for hypnosis and had 24 sessions over eight months, but there was no change in the incidence of ulceration, though the lesions became smaller and lasted for a shorter time during therapy.

CASE 4 C.N., a married woman aged 32, had one child. She had Behcet's disease with fleeting polyarthropathy and recurrent ulceration of the mouth, pharynx, vulva, and skin for 14 years, with onset at the time of her parents' divorce. She was an intelligent but hypersensitive personality. Previous treatment included repeated courses of systemic corticotrophin and systemic and local corticosteroids over the past 10 years. She also had hydroxyquinolone and triamcinolone in orabase. She was a fairly good subject for hypnosis but difficult to keep at the level of post-hypnotic suggestion. She had six sessions over three months, but hypnosis had no effect 
on the incidence and severity of the buccal or vulval lesions.

CASE 5 I.R., a widow aged 61 years, had a history of continuous atrophic stomato-glossitis with debased, superficially ulcerated, epithelium of the lips, buccal cavity, and tongue for eight years. She was a pathetically dependent, inadequate personality with episodic depression. Associated with the ulcers she had atrophic gastritis with mixed iron and vitamin $\mathbf{B}_{12}$-deficiency anaemia. There was no response of the buccal state to full correction of the anaemia, nor to antidepressive agents, highpotency vitamins, ethinyloestradiol, and local corticosteroids. Hypnosis was begun when the mouth and tongue were severely inflamed. Twelve sessions were given over four months. After six sessions the mouth was subjectively and objectively the best it had been for several years. Atrophic thinning of the epithelium of the mouth and tongue continued but hyperaemia, fissures, and erosions disappeared. Three months after cessation of hypnosis improvement was maintained and she is still without a relapse 12 months later.
COMMENT

Of the four cases of recurrent aphthous ulceration of the mouth, including one with the features of Behcet's disease, none derived any significant benefit from hypnosis. In one subject with a dependent, suggestible personality with atrophic glossostomatitis, a striking improvement occurred while she was receiving the treatment. Despite the apparent association of potentially strong psychomatic factors with the aphthous type of mouth ulceration, hypnosis failed to prove of more benefit than has been shown to follow the sympathetic interest of a physician without the use of drugs.

\section{REFERENCES}

Sircus, W., Church, R., and Kelleher, J. (1957). Recurrent aphthous ulceration of the mouth. Quart. J. Med., 26, 235-249.

- (1959). The management of recurrent aphthous stomatitis. Brit. med. J., 2, 804-806. 